Research Article

\title{
Experimental Research on Mechanical Property and Environmental Safety of an Industrial Residue Waste Subgrade Material
}

\author{
Yangpeng Zhang, ${ }^{1,2,3,4}$ Jianping Xiong, ${ }^{1,2,3,4}$ Qinglin Li $\left(\mathbb{D},{ }^{5}\right.$ and Jiuhui Cui ${ }^{6}$ \\ ${ }^{1}$ Guangxi Transportation Science \& Technology Group Co., Ltd., Nanning 5300007, China \\ ${ }^{2}$ Guangxi Key Lab of Road Structure and Materials, Nanning 5300007, China \\ ${ }^{3}$ Research and Development Center on Technologies, Nanning 5300007, China \\ ${ }^{4}$ Materials and Equipment of High-Grade Highway Construction and Maintenance Ministry of Transport, \\ Nanning 5300007, China \\ ${ }^{5}$ College of Water and Architectural Engineering, Shihezi University, Shihezi 832003, China \\ ${ }^{6}$ China Bluestar Chengrand Co., Ltd., Chengdu 610000, China
}

Correspondence should be addressed to Qinglin Li; liql1150142@163.com

Received 13 June 2020; Accepted 24 July 2020; Published 12 August 2020

Guest Editor: Guocheng Lv

Copyright (C) 2020 Yangpeng Zhang et al. This is an open access article distributed under the Creative Commons Attribution License, which permits unrestricted use, distribution, and reproduction in any medium, provided the original work is properly cited.

\begin{abstract}
In order to promote the sustainable use of oil shale residues, a novel subgrade material (SOF) composed of silty clay, oil shale ash residue, and fly ash was developed. The aim of this paper is to study the mechanical behavior and environmental impact of SOF, which is regarded as the safety assessment and prediction for the application of this novel material. To this purpose, the road performance, dynamic properties, and environment impact tests are conducted. In terms of the road performance, the test results of SOF exceed the standard requirement, especially for CBR (California bearing ratio), which can maintain good performance at bad conditions of low compaction degree and being soaked for a long time. The dynamic properties under cyclic loadings are better than most of original and stabilized soils. The shear strength parameters and the anti-damage mechanism are also discussed; research results show that the friction of SOF mostly contributes to shear strength under high stress conditions, while its cohesion tends to play a more important role under low stress conditions. According to the deformation variation, the accumulation settlement of SOF under vehicle loadings after several years is predicted, which is far lower than the limit of expressway and Grade I highway. Furthermore, the chemical stability and toxicity of SOF leachates are environmentally friendly, which are in line with the benchmarks of Class II surface water and Class III ground water. All the experimental results manifest that SOF used as subgrade filling has good application potential and safety.
\end{abstract}

\section{Introduction}

As the nonrenewable fossil energy like petroleum, gas, and coal, the utilization of oil shale has a history of nearly 200 years in terms of distribution situation, basic properties, extraction technology, and applied research [1]. With higher ash and oil content than coal, oil shale is processed into gasoline, diesel, and burning oil and is co-exploited with coal as associated resources. In China, the detected oil shale reserves of approximately 72 billion tons rank among the top in the world. According to the preliminary exploration by the government [2], a national oil shale reserve distribution map is drawn in Figure 1. Due to abundant oil shale resources, there are more than 10 oil shale retorting companies in service. Therefore, a large amount of oil shale waste residue has also been generated with the continuous development. From incomplete statistics, China's annual production of shale oil reaches 700,000 tons with by-product wastes of 1.75 million tons $[3,4]$.

The recycle of oil shale wastes mainly focuses on the aspects of construction materials, fertilizer, and soil stabilization, which follows the application experience of fly ash, 


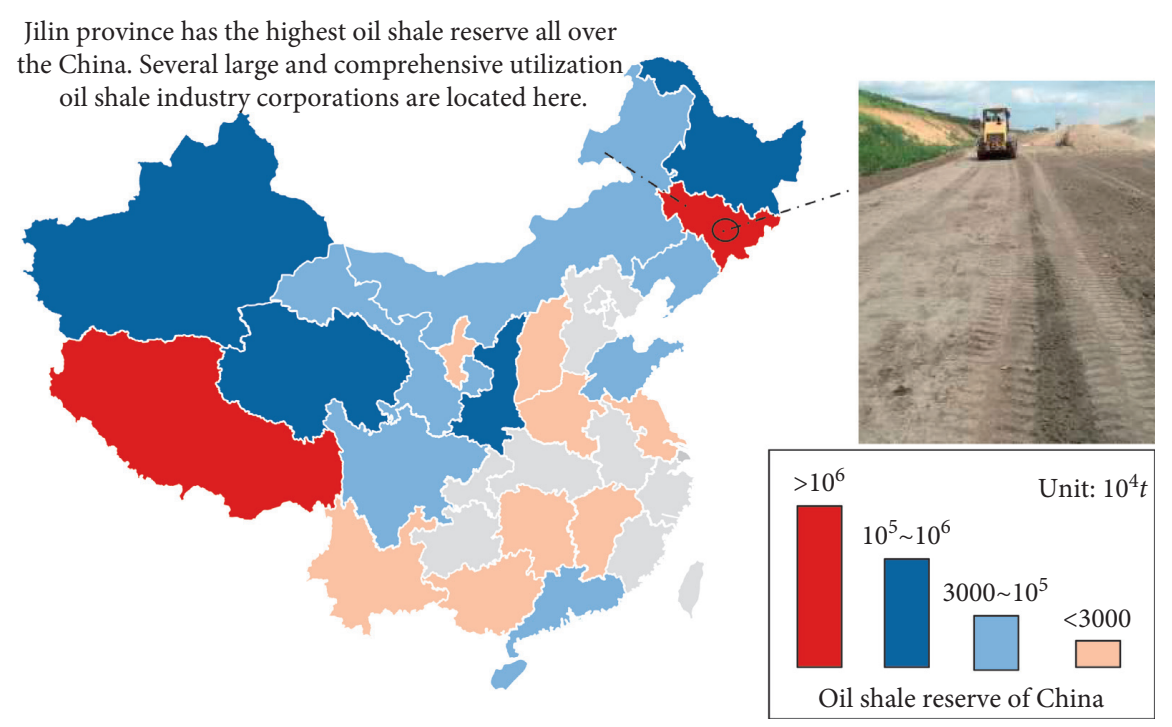

Figure 1: Distribution of oil shale resources in China.

mineral slags, and so on $[5,6]$. Recently, with the rapid development of China's highway, industry-industrial wastes have been widely used in road structures. Taking the reuse of waste tires as an example, the processed crumb rubbers by cutting and grinding tires have been applied in asphalt and related road products. Similar applications are also conducted for fly ash and slags. Compared with the utilization of other wastes, the current application of oil shale wastes is in the early stage. Azzam and Al-Ghazawi [7] added oil shale wastes into hot mix asphalt based on Superpave design method. The result indicated that the mixed asphalt possessed favorable performance in aspects of resilient modulus, creep, and fatigue tests. Wang et al. [8] investigated the positive impact of oil shale wastes on the temperature properties of asphalt mastics and observed the difference between oil shale ash and semi-coke when they were used as the filling material of asphalt mastics.

Subgrade is a broad field for the application of oil shale wastes. Turner stabilized soils by OSA (oil shale ash) and established the corresponding database of engineering properties $[9,10]$, and it was also found that the combination of OSA and limestones showed better road performance. To dispose the byproduct OSA of Narva Power Plant, Koroljova and Pototski [11] added the residues to soft peat soils to replace the traditional addition of cement. Since 2013, this technology has been widely used for road construction in swamp areas of Estonia [12]. The group of Jilin University also carried out a comprehensive research on the modification of OSA as subgrade materials; an economical and efficient method for the utilization of OSA has been proposed after a series of tests, including basic physical characteristics, material proportion, and mechanical properties [13-15].

In view of the huge advantages of this novel filling, authors and the local transportation department are conducting an experimental road to accumulate more experience and foundation for further application. As a matter of fact, the process of development, application, and promotion for a new subgrade material requires a long-term verification on performance, economy, and safety. To a certain extent, safety assessment holds the first priority. For the filling of SOF, even though a systematic research has been conducted, there are still significant and necessary works worth studying, for example, the mechanical response and deformation characteristics under actual vehicle loadings and the evaluation of durability and chemical composition stability, which are also the purpose and main contents of this paper.

Road performance is the earliest but the most important factor in the evaluation of the feasibility of subgrade. It can be analyzed from CBR, resilient modulus, unconfined compressive tests, and so on. Mohajerani et al. [16] researched the road performance of modifying the biosolid wastes of Melbourne East and West Plant by lignite fly ash based on a series of CBR tests. Deb and Narnaware [17] adopted the unconfined compressive strength to determine the effectiveness of fiber on clay. The recognized mixing ratio of $1: 2$ of fly ash on soil is also found by means of road performance tests. With the deep understanding of road structure and failure mechanism, more property of materials has been concentrated on, such as mechanical strength and deformation characteristics. Murthy et al. investigated the dynamic modulus and damping ratio of the cement-stabilized soils by triaxial tests [18]. Research results showed that the microporous soils, with the addition of cements, possessed high dynamic strength and better resistance to deformation. The similar conclusions had been got by Baig et al. [19]. To discuss the deformation characteristics of saturated friable sand modified by silica slurry, Gallagher and Mitchell [20] conducted parallel cyclic vibrations with different addition amounts and stress conditions. They obtained the positive results for total axial deformation and liquefaction strength. Based on summarizing the previous research, the above evaluation methods of the dynamic characteristic of subgrade have been mature and effective.

As mentioned above, the objective of this study is to perform the safety assessment of SOF, which is regarded as the vital prediction and reserved information for the 


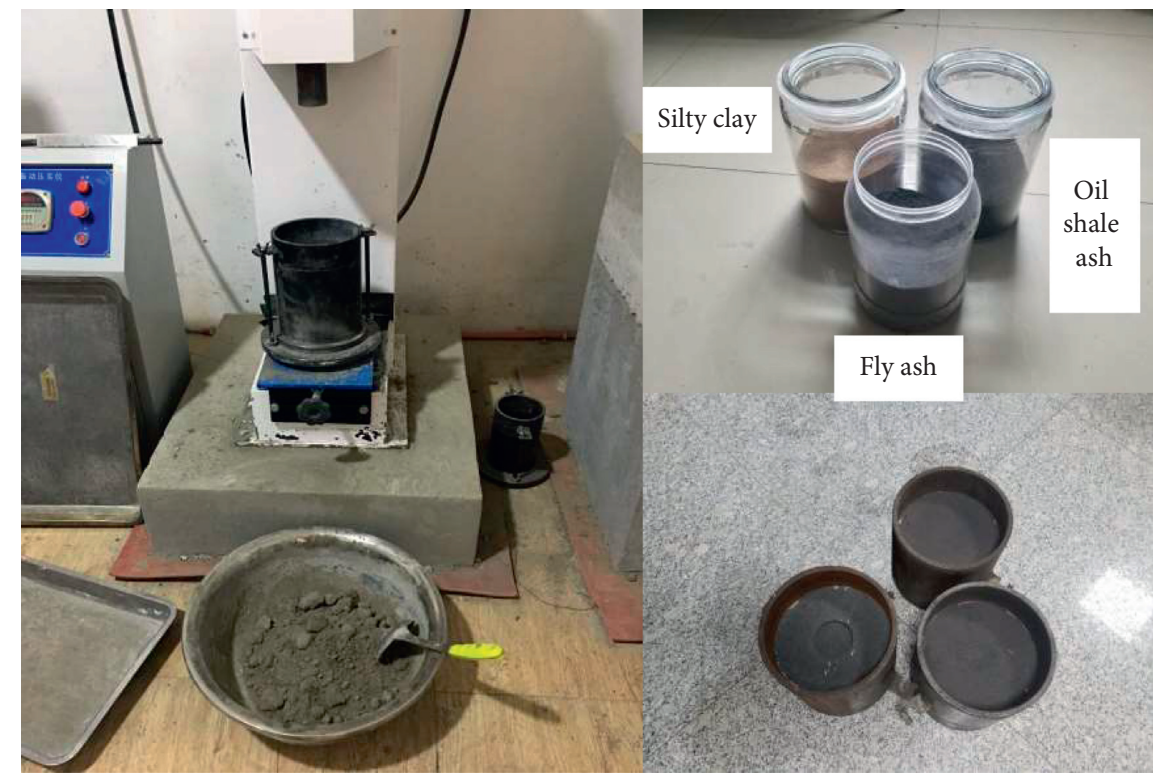

Figure 2: Preparation of test samples.

construction of experimental road. To this purpose, a series of experiments of CBR, static resilient modulus, dynamic strength, and deformation are conducted to investigate the road performance and mechanical properties of modified soils. Further analysis from the aspects of shear failure and accumulation deformation is also conducted. Finally, to master the environmental suitability of this novel filling material, a comprehensive evaluation of chemical composition stability and toxicity is performed.

\section{Material Properties and Experimental Methods}

2.1. Physical Properties of SOF. The material of SOF is made by evenly mixing silty clay, oil shale ash, and fly ash at the mass ratio of $2: 2: 1$, and before making testing samples, oil shale ash, silty clay, and fly ash samples were dried in an oven at $105-110^{\circ} \mathrm{C}$ for $24 \mathrm{~h}$ and then cooled at room temperature in a desiccator. The sample preparation of road performance test is shown in Figure 2, and the preparation process follows the impact molding method [21]. Silty clay is the typical bad filling in northeast China because of its undesirable water instability. Oil shale ash is completely provided by the nearby oil shale industrial park, which is collected by the combustion of oil shale ores. The range of particle size $0-5 \mathrm{~mm}$ guarantees the activity to be used in construction material improvement, fertilizer production, and stabilization of soft soils. The fly ash used in this study is classified into F Class with the content of $\mathrm{CaO}$ of $0.92 \%, \mathrm{SiO}_{2}+\mathrm{Al}_{2} \mathrm{O}_{3}+\mathrm{Fe}_{2} \mathrm{O}_{3}$ of $88.64 \%$, and the loss on ignition of $3.19 \%$.

\subsection{Experimental Methods}

2.2.1. Road Performance Test. In the specification of design for highway subgrades [22], road performance of CBR and resilient modulus are mandatory indexes to evaluate the serviceability of subgrade materials. Road materials strength tester and lever tester are adopted to measure the above two parameters, respectively. According the national standard [21], testing specimens (the height of $170 \mathrm{~mm}$, the diameter of $76 \mathrm{~mm}$ ) are produced by heavy compaction method at the degrees of $96 \%$ and $100 \%$. Three parallel specimens are also designed for each test condition. Moreover, for the CBR tests, the test specimens are soaked with water for $96 \mathrm{~h}$ in order to simulate the worst service environment.

2.2.2. Dynamic Properties Test. For subgrade materials, dynamic properties are more available for assessing the application safety in practical engineering, especially for constructions in seasonally frozen regions. So, the strength and deformation characteristics related to dynamic loadings are tested in this part. The dynamic triaxial testing system, made in Gansu, China, is used in this part. Cylindrical specimens with a diameter of $39.2 \mathrm{~mm}$ and a height of $80 \mathrm{~mm}$ are prepared according to the national standard [21]. To make the results more realistic for the site, the states of saturated water and F-T (freeze-thaw) cycles are also designed.

In testing strength characteristics, all specimens are brought to outer vacuum saturation for $24 \mathrm{~h}$ and backpressure saturation in device. An initial axial stress is added to consolidate specimens with a factor of 1.9. The confining pressure varies from 50 to $150 \mathrm{kPa}$, and the vibration frequency is set as $1 \mathrm{~Hz}$. Furthermore, several parallel experiments are conducted for specimens after 1, 3, 5, and 7 F-T cycles. A F-T cycle means the test specimen is frozen at the temperature of $-15^{\circ} \mathrm{C}$ and then thawed at the temperature of $15^{\circ} \mathrm{C}$ for $24 \mathrm{~h}$. During this process, the specimens are sealed with plastic film to reduce the moisture change and external impact. There is another long-term deformation experiment to test the deformation characteristics of SOF. The specimens are performed at the optimum moisture and dry 
density. All experiment procedures are carried out in the confining pressures of $100 \mathrm{kPa}$ with the vertical stress ratio of 0.5 and 1.5. The confining pressure of $100 \mathrm{kPa}$ is chosen because it is the closest situation to the application engineering. Similar tests are repeated for specimens after different F-T cycles as well.

2.2.3. Chemical Composition Test. Road performance and mechanical property are the essential premise to judge the serviceability of subgrade filling. However, the safety assessment of subgrade filling on the surrounding environment also cannot be ignored. The potential threats of SOF on the environment are related to its chemical composition and precipitated trace elements after immersion in water. In this part, the detailed analysis of the composition of SOF and its leachates are conducted at Testing Center of Jilin University; the XRD (x-ray diffraction), FTIR (Fourier transform infrared spectroscopy), and ICPMS (inductively coupled plasma-mass spectrometry) are adopted in the analysis.

\section{Results and Discussion}

3.1. Road Performance of SOF. The results of CBR and resilient modulus for SOF are listed in Tables 1 and 2. In Table 1, the CBR values of SOF at the compaction degree of $100 \%$ are slightly higher than those at the degree of $96 \%$. The same phenomenon is reflected in the measured resilient modulus in Table 2. This can be attributed to the denser structure of specimens during forming process. The water absorption and swelling capacity of $6.92 \%$ and $5.47 \%$ at the maximum compaction condition are lower than the results of $7.62 \%$ and $5.84 \%$ at the compaction degree of $96 \%$, which indicates the small distinction in structure. It also should be noted that the CBR values of specimens treated by soaking decline sharply by $46.2 \%$ and $45.4 \%$. The result proves the effect of bad service environment of subgrade on the road performance.

For subgrade materials, explicit standard is required for the road performance. For expressway and first-class highway, the regulated minimum CBR values of roadbed and embankment are 5\% 8\% and $3 \% \sim 4 \%$, respectively. The minimum resilient modulus of upper roadbed for cement concrete and bituminous pavement at the extremely heavy or heavy traffic load is 80 and $70 \mathrm{MPa}$, respectively. Taking into account the compaction difficulty in actual construction, the results of $\mathrm{CBR}$ and resilient modulus at the compaction of $96 \%$ are used as the evaluation index of road performance for SOF. Both CBR and resilient modulus are far higher than the specified standard, especially for CBR. The good performances of SOF are related to the stable structure formed by fly ash and oil shale ash, which has been mentioned in a previous study [13]. Thus, the road performance of SOF is considered safe even at some undesirable conditions.

3.2. Dynamic Strength Characteristics. Dynamic failure strength $\sigma_{\mathrm{s}}$ is the most acknowledged parameter to evaluate the dynamic properties of soils. In this paper, $\sigma_{s}$ is defined as the half value of $\sigma_{\mathrm{d}}$ when the axial strain exceeds $5 \%$. The relationship curves of $\sigma_{\mathrm{s}}$ and $\log (n)$ (where $n$ represents the vibration numbers of failure) of SOF under the pressures of 50,100, and $150 \mathrm{kPa}$ are drawn in Figure 3. As shown in Figure 3, $\sigma_{\text {s }}$ possesses higher values when the confining pressure is higher, and is a good linear decrease relation with $\log (n)$. The higher the confining pressure, the faster the decline rate. For example, the gradient of $111.44 \sim 125.44$ under $\sigma_{\mathrm{c}}$ of $150 \mathrm{kPa}$ is nearly $3.56 \sim 4.43$ times that under $\sigma_{\mathrm{c}}$ of $50 \mathrm{kPa}$, which indicates that the effect of confining pressure on the failure strength is gradually weakened as the vibration numbers increase. The action of F-T cycles is another important factor influencing the failure strength. Comparing the results under the same testing conditions, $\sigma_{\mathrm{s}}$ decreases sharply after F-T cycles especially for the situation of high confining pressure, and the linear relationship between $\sigma_{s}$ and $\log (n)$ is still obvious after F-T cycles. Furthermore, from the perspective of numerical values, the dynamic properties under cyclic loadings are better than those of most of original and stabilized soils [23, 24]. Therefore, the filling material of SOF can be classified as a high-strength subgrade material.

To understand the dynamic strength characteristics of SOF more deeply, shear strength parameters including dynamic cohesion $c_{\mathrm{d}}(\mathrm{kPa})$ and dynamic inter friction angel $\varphi_{\mathrm{d}}\left({ }^{\circ}\right)$ can be obtained by Mohr-Coulomb Curve. Just as shown in Figure $4, \sigma_{\mathrm{c} 1}, \sigma_{\mathrm{c} 2}$, and $\sigma_{\mathrm{c} 3}$ are confining pressures of 50,100 , and $150 \mathrm{kPa}$, respectively; $\sigma_{\mathrm{a} 1}, \sigma_{\mathrm{a} 2}$, and $\sigma_{\mathrm{a} 3}$ are the axial failure principal stress $(\mathrm{kPa})$ corresponding to the above three confining pressures, respectively. According to the experiment schedule, the value of axial failure principal stress can be calculated as follows:

$$
\begin{aligned}
\sigma_{\mathrm{d}} & =2 \sigma_{\mathrm{s}}, \\
\sigma_{\mathrm{a}} & =\sigma_{1}+\sigma_{\mathrm{d}}, \\
\sigma_{\mathrm{i}} & =k \times \sigma_{\mathrm{c}},
\end{aligned}
$$

where $\sigma_{\mathrm{i}}$ is the initial static axial stress on the specimens $(\mathrm{kPa})$ and $k$ is the consolidation coefficient of 1.9. Based on the theory of ultimate equilibrium, the failure envelope, which is the common tangent of three Mohr circles, can be drawn. Then, $c_{\mathrm{d}}$ and $\varphi_{\mathrm{d}}$ are obtained by measuring the intercept and slope of the failure envelope by Lambe plane $(s, t)$ method. Taking into account the significant influence of the physical property and experimental stress condition on specimens, the parameters of $c_{\mathrm{d}}$ and $\varphi_{\mathrm{d}}$ at different failure points and F-T cycles are separately calculated in this part. The relation functions of $t=\left(\sigma_{\mathrm{a}}-\sigma_{\mathrm{c}}\right) / 2$ and $s=\left(\sigma_{\mathrm{a}}+\sigma_{\mathrm{c}}\right) / 2$ are plotted in Figure 5. The calculated shear strength parameters of SOF under different testing conditions are listed in Table 3.

From Table 3, some valuable conclusions can be obtained. The dynamic friction angle $\varphi_{\mathrm{d}}$ and cohesion $c_{\mathrm{d}}$ vary with the vibration numbers of failure which proves the significant influence of stress conditions on specimens. As the failure number increases, the parameter of $\varphi_{\mathrm{d}}$ decreases whereas $c_{\mathrm{d}}$ increases. It means the friction mostly 
TABLE 1: Results of CBR test.

\begin{tabular}{|c|c|c|c|c|c|c|c|c|c|}
\hline \multirow{2}{*}{$\mathrm{CD}^{1}(\%)$} & \multirow{2}{*}{ No } & \multicolumn{4}{|c|}{ Water absorption and swelling capacity } & \multicolumn{4}{|c|}{ CBR values } \\
\hline & & $\mathrm{WA}^{2}(\%)$ & Average/SD ${ }^{3}(\%)$ & $\mathrm{SI}^{4}(\%)$ & Average/SD $3(\%)$ & $\mathrm{CBR}_{\mathrm{s}}^{5}(\%)$ & Average/SD ${ }^{3}(\%)$ & $\mathrm{CBR}_{\mathrm{ws}}{ }^{6}(\%)$ & Average/SD 3 (\%) \\
\hline \multirow{3}{*}{100} & 1 & 7.01 & & 5.42 & & 41.79 & & 79.52 & \\
\hline & 2 & 6.98 & $6.92 / 0.14$ & 5.51 & $5.47 / 0.05$ & 44.11 & $42.37 / 1.53$ & 78.65 & $78.74 / 0.73$ \\
\hline & 3 & 6.76 & & 5.48 & & 41.21 & & 78.06 & \\
\hline \multirow{3}{*}{96} & 1 & 8.12 & & 5.92 & & 38.86 & & 71.38 & \\
\hline & 2 & 7.34 & $7.62 / 0.43$ & 5.83 & $5.84 / 0.07$ & 38.39 & $38.41 / 0.44$ & 69.14 & $70.16 / 1.13$ \\
\hline & 3 & 7.41 & & 5.78 & & 37.99 & & 69.96 & \\
\hline
\end{tabular}

${ }^{1} \mathrm{CD}=$ compaction degree; ${ }^{2} \mathrm{WA}=$ water absorption; ${ }^{3} \mathrm{SD}=$ standard deviation; ${ }^{4} \mathrm{SI}=$ swelling increment; ${ }^{5} \mathrm{CBR}_{\mathrm{s}}=\mathrm{CBR}_{\text {soaked }}$ with water; ${ }^{6} \mathrm{CBR}$ ws $=\mathrm{CBR}$ without soaking.

TABLE 2: Results of resilient modulus test.

\begin{tabular}{lcccr}
\hline \multirow{2}{*}{$\mathrm{CD}^{1}(\%)$} & \multicolumn{3}{c}{ Resilient modulus (MPa) } \\
& Value 1 & Value 2 & Value 3 & Average/SD \\
\hline 100 & 133.56 & 136.42 & 137.63 & $135.87 / 2.09$ \\
96 & 121.34 & 124.48 & 126.82 & $124.21 / 2.75$ \\
\hline
\end{tabular}

${ }^{1} \mathrm{CD}=$ compaction degree. ${ }^{2} \mathrm{SD}=$ standard deviation.

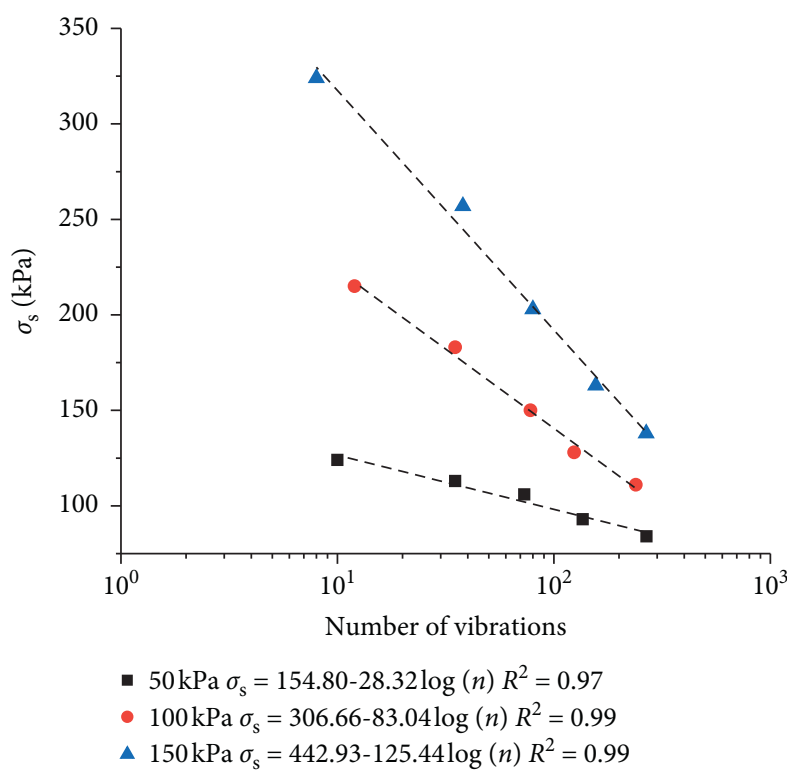

(a)

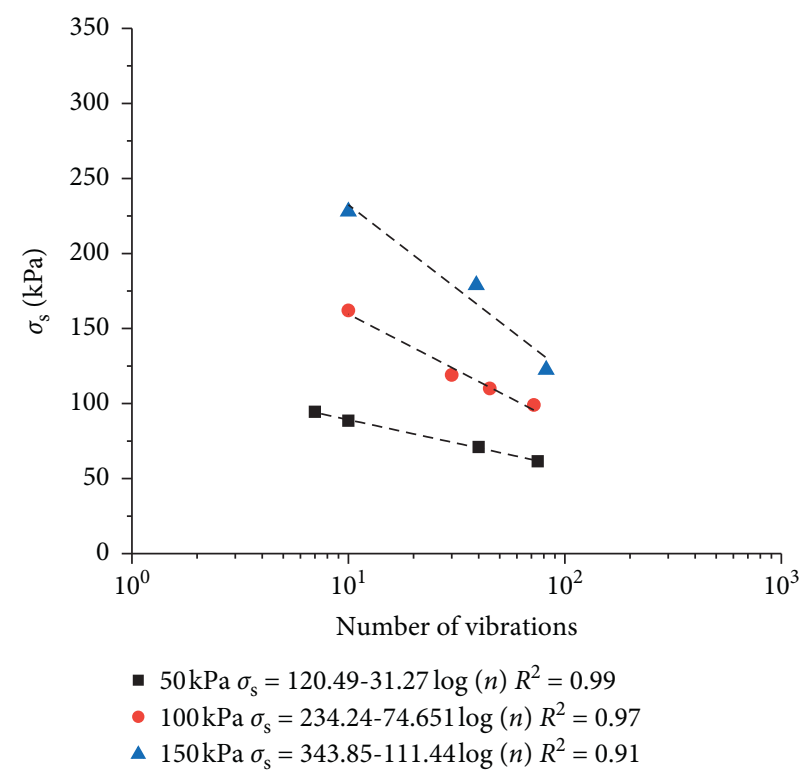

(b)

Figure 3: Dynamic strength of SOF. (a) Before F-T cycles. (b) After F-T cycles.

contributes to shear strength under high stress conditions, while the cohesion tends to play a more important role under low stress conditions. Furthermore, the friction angle and cohesion of SOF decrease at the ratio of $9.2 \% \sim 12 \%$ and $30 \% \sim 45 \%$ under the same testing condition after F-T cycles, which verifies the above conclusion.

3.3. Long-Term Deformation Characteristics. Figure 6 shows long-term deformation diagrams of SOF subjected to 8000 cyclic loadings. In the figure, the area swept by the graphic strips is the deformation range, where the upper edge represents the maximum elastic deformation and the lower edge is the minimum permanent deformation. The deformation remains as large values at the condition of higher vertical stress after F-T cycles. All deformation curves increase sharply during the first 500 cyclic loadings and then tend to be at a steady growth, which reflects the typical plastic characteristics of SOF. The stress-strain hysteresis ring of the first and 8000th vibration is shown in Figure 7, where the slight elasticity decay can be found. Moreover, according to traditional calculated expressions, the resilient modulus of SOF subjected to long-term cyclic vibrations is derived and shown in Figure 8. Just as the figure describes, 


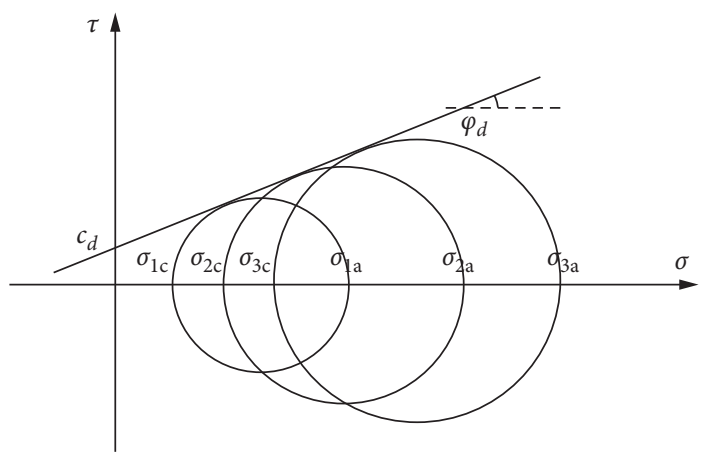

FIgURE 4: Diagram of Mohr-Column strength method.

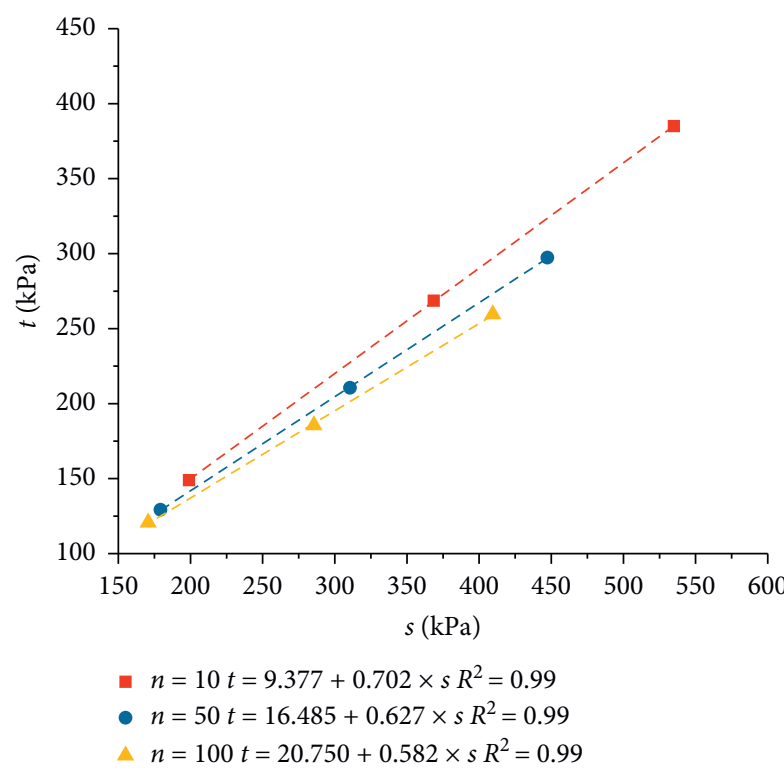

(a)

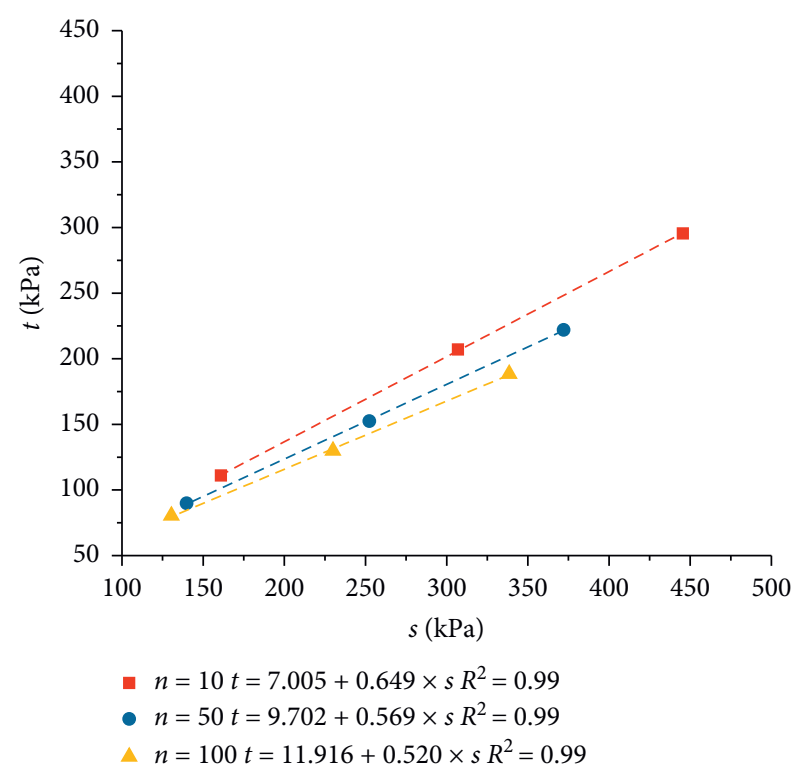

(b)

Figure 5: S-t diagrams for the test soils. (a) Before F-T cycles. (b) After F-T cycles.

TABLE 3: Shear strength parameters of test specimens.

\begin{tabular}{lccc}
\hline \multirow{2}{*}{ F-T state } & Vibration numbers of failure & \multicolumn{2}{c}{ Strength } \\
& $(n)$ & $\varphi_{\mathrm{d}}$ & $c_{\mathrm{d}}$ \\
\hline \multirow{2}{*}{ Without F-T } & 10 & 44.59 & 13.17 \\
cycles & 50 & 38.83 & 21.16 \\
& 100 & 35.59 & 25.52 \\
\hline \multirow{2}{*}{ After F-T cycles } & 10 & 40.47 & 9.21 \\
& 50 & 34.68 & 11.80 \\
& 100 & 31.33 & 13.95 \\
\hline
\end{tabular}

the resilient modulus exhibits a small attenuation. The deformation performance is far better than that of other subgrade filling materials $[25,26]$.

For subgrades, the accumulation deformation under repeated vehicle loadings is a very important index to assess the long-term stability of road structure. There are specified requirements for subgrade of highway and railway in China
$[27,28]$. Figure 9 shows the detailed deformation curve of SOF during the first 10 cyclic vibrations. Lines $A$ and $B$, corresponding to the fitting curves of minimum deformation points and force equilibrium points, are usually taken to predict the potential deformation of filling materials under long-term repeated loadings. In this part, Line B is adopted to fit the deformation points in the form of following equation:

$$
\varepsilon=A n^{b}
$$

where $\varepsilon$ represents the accumulation deformation (\%), $n$ represents the vibration numbers, and $A$ and $b$ are fitting parameters. The calculated results are shown in Table 4 .

In Table 4 , the fitting model presents a good credibility. The fitting parameters of $A$ and $b$ change from 0.063 to 0.447 and 0.078 to 0.139 , respectively. The effects of stress and F-T cycles on $A$ and $b$ are not reflected apparently. The variation trend of accumulation deformation is determined by the product of parameters $A$ and $b$. Based on the traffic statistic 


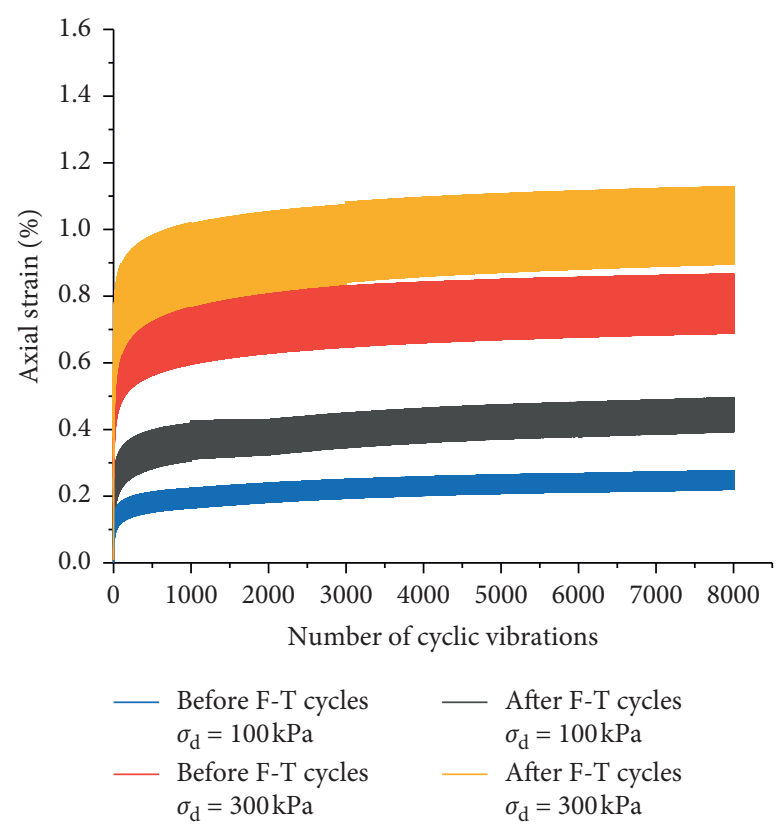

Figure 6: Long-term deformation curves of SOF.

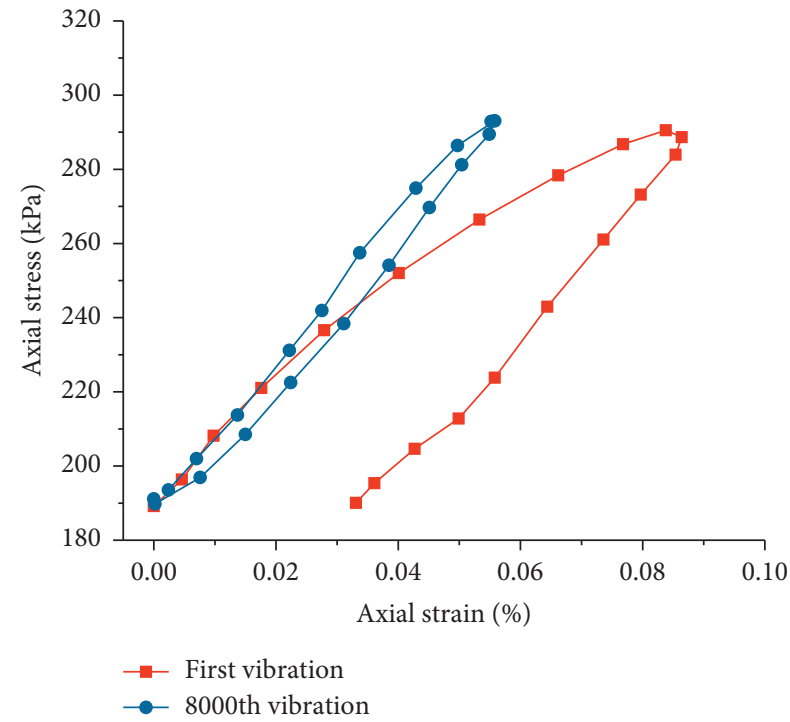

Figure 7: Stress-strain rings of the 1st and 8000th vibration.

data, 10 million vibrations are used to predict the residual deformation of SOF subgrade after operation of several years. Furthermore, taking account of the worst service environment, the fitting result at the deviator stress of $300 \mathrm{kPa}$ after F-T cycles is adopted. The calculated accumulation strain is $1.57 \%$. Consequently, the calculated accumulation deformation is $0.79 \mathrm{~cm}$ with the filling thickness of $50 \mathrm{~cm}$, which is far lower than the limit of $10 \mathrm{~cm}$ for expressway and Grade I highway.

After large numbers of vehicle loads, the deformation of SOF is similar to the dynamic strength, which show good road performance and F-T durability related to the structure of SOF. According to the previous research by the authors [13], it is found that the particles of SOF are small and

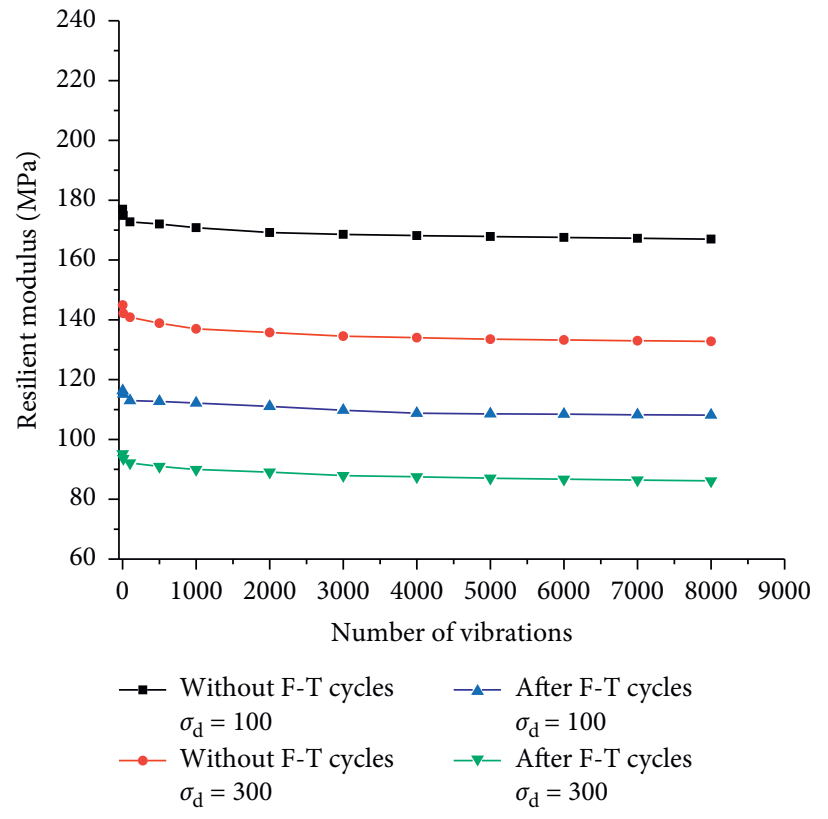

FIGURE 8: Resilient modulus of SOF during large times of vibration.

uneven and have no obvious direction. The particles are interconnected by cementation and binding water to form an agglomerate-plate structure, which possesses good mechanical fatigue characteristics, especially for the F-T environment, because fine particles will soon find new stable structures and quickly shape, and then maintain relatively stable performance.

3.4. Environment Impact Assessment of SOF. The x-ray diffraction reflectogram and spectra of FTIR for three raw materials and SOF are shown in Figures 10 and 11, respectively. Furthermore, the parallel tests of SOF after F-T 


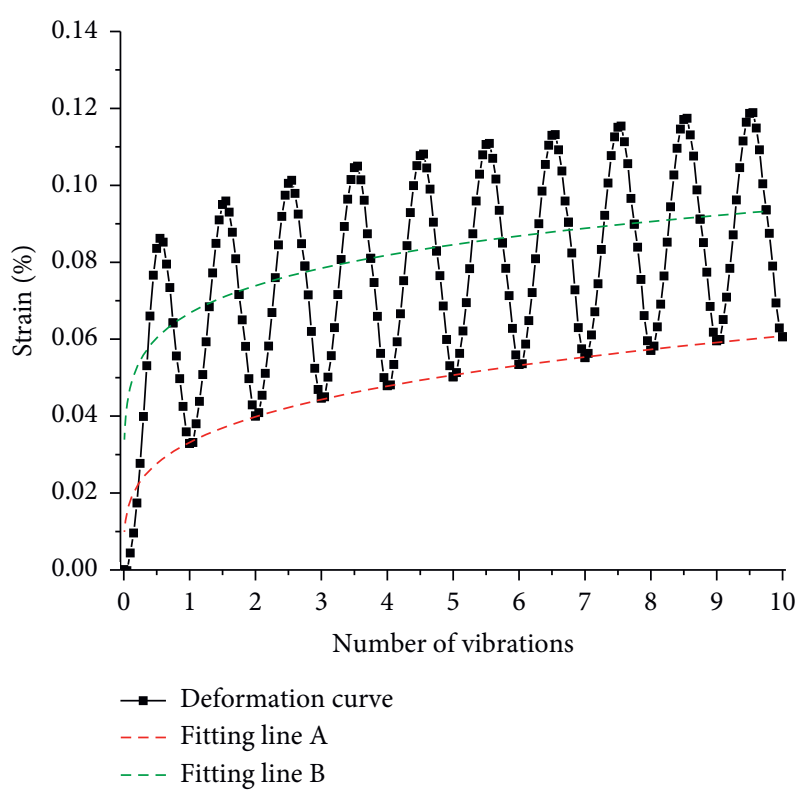

FIGURE 9: Detailed deformation curve of SOF during the first 10 cyclic vibrations.

TABLE 4: Fitting results of long-term deformation prediction model.

\begin{tabular}{|c|c|c|c|c|}
\hline \multirow{2}{*}{ Testing state } & \multirow{2}{*}{ Deviator axial stress $(\mathrm{kPa})$} & \multicolumn{3}{|c|}{$\varepsilon=A n^{b}$} \\
\hline & & $A$ & $b$ & $R^{2}$ \\
\hline \multirow{2}{*}{ Without F-T cycles } & 100 & 0.063 & 0.139 & 0.986 \\
\hline & 300 & 0.349 & 0.076 & 0.989 \\
\hline \multirow{2}{*}{ After F-T cycles } & 100 & 0.127 & 0.125 & 0.983 \\
\hline & 300 & 0.447 & 0.078 & 0.993 \\
\hline
\end{tabular}

cycles are also carried out. In figures, the fluctuations of the reflectogram and waveforms represent the corresponding substances, and the higher peak represents the larger content of the substance. Consequently, the mineral compositions of specimens are listed in Table 5. Just as shown, the fluctuations of oil shale, fly ash, and silty clay are all reflected in SOF, and the peaks are basically consistent with the superimposed values at the mix ratio. However, some subtle differences are still worth discussing, especially for the effect of F-T cycles on SOF. In Figure 10, the fluctuation in 2-theta of $27.5^{\circ}$ is slightly fiercer after F-T cycles, which represents the transformation of potassium feldspar to plagioclase in SOF. The same situation occurs in the wave number of $1425 \mathrm{~cm}^{-1}$ in Figure 11, where amorphous calcium carbonates generate. Furthermore, the wave fluctuations in the wave number of 916 and $3620 \mathrm{~cm}^{-1}$ of Figure 11 disappear during the mixing process and regenerate after F-T cycles, which is the change manifestation of hydroxyl substances. For the safety assessment of SOF, the small amount of chemical bonds transformation and morphological substance exhibit little effect on the overall material composition. Therefore, it can be concluded that the chemical composition of SOF is stable enough.

The potential hazards of SOF leachates on environment are derived from their toxicity and corrosivity. The surface and ground water standard of China $[29,30]$ are used to judge the negative impact of leachates on the surrounding

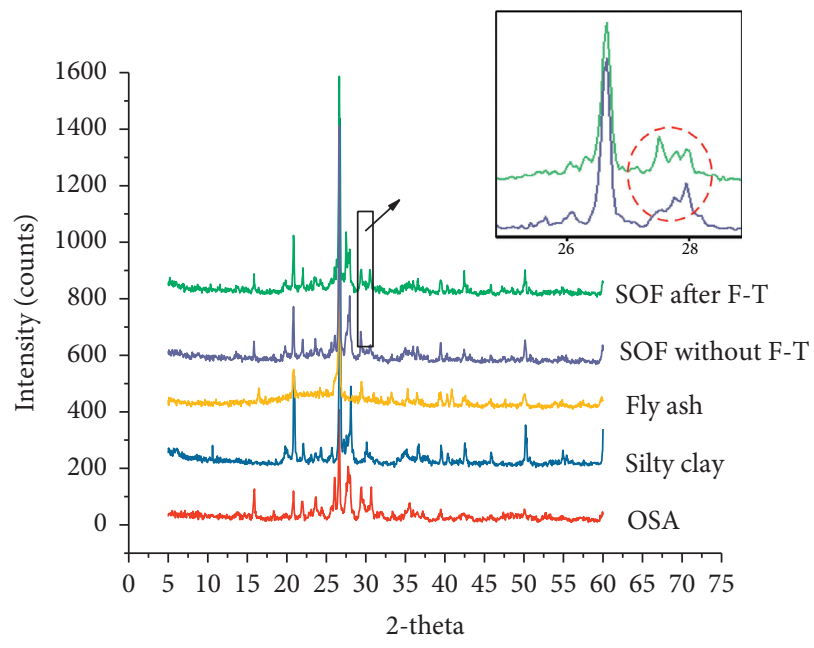

FIgURE 10: X-ray diffraction reflectograms of test soils.

water resources. As seen from Table 6, the concentration of trace elements plays a more decisive role than that of cations and anions. The soil leachates are in line with the benchmarks of Class II surface water and Class III ground water, which accords with the domestic water for drinking, breeding, and agriculture production. Moreover, SOF can be classified as the alkaline soil based on the $\mathrm{pH}$ value. The 


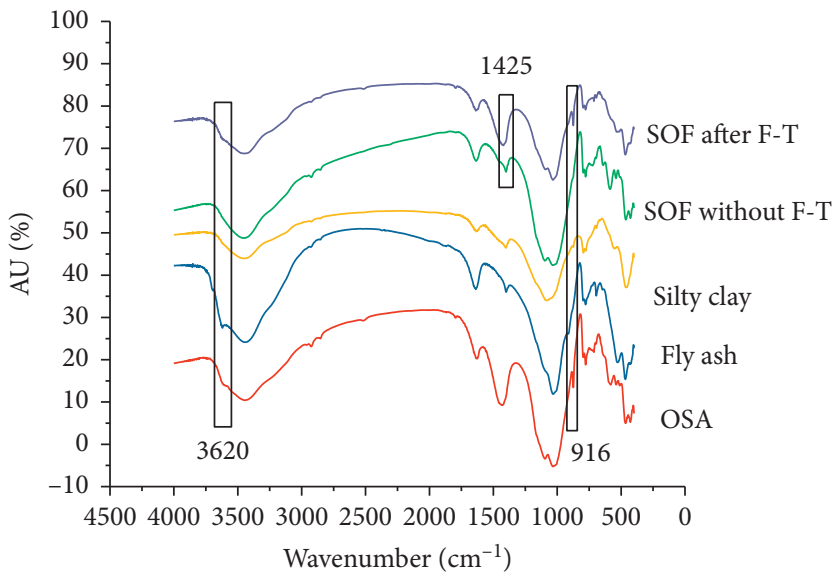

FIGURE 11: FTIR analysis for test soils.

TABLE 5: Mineral composition of raw materials and SOF.

\begin{tabular}{lcccc}
\hline Composition & OSA (\%) & Fly ash (\%) & Silty clay (\%) & SOF (\%) \\
\hline Quartz & 25 & 50 & 30 & 32 \\
Plagioclase & 8 & 12 & -- & 8 \\
Orthoclase & -- & 2 & -- & 1 \\
Analcime & 5 & -- & -- & 2 \\
Calcite & 10 & -- & -- & 4 \\
Kaolinite & -- & 5 & -- & 1 \\
Illite/montmorillonite & 48 & 30 & 10 & 4 \\
Mullite & -- & -- & -- & 2 \\
Organic material & 4 & 1 & 60 & 13 \\
Amorphous & -- & -- & & \\
\hline
\end{tabular}

TABLE 6: Chemical composition analysis of SOF leachates.

\begin{tabular}{|c|c|c|}
\hline Test items & Contents & Standard \\
\hline Concentration of cations and anions & $\mathrm{Na}^{+}, \mathrm{K}^{+}, \mathrm{Ca}^{2+}, \mathrm{Mg}^{2+}, \mathrm{NH}_{3}-\mathrm{N}, \mathrm{Cl}^{-}, \mathrm{SO}_{4}^{2-}, \mathrm{CO}_{3}^{2-}, \mathrm{NO}_{3}^{-}, \mathrm{F}^{-}, \mathrm{PO}_{4}^{-}$ & $\begin{array}{l}\text { Surface water (Class I) } \\
\text { Ground water (Class I) }\end{array}$ \\
\hline Concentration of trace elements & $\mathrm{Al}, \mathrm{As}, \mathrm{Ba}, \mathrm{Cd}, \mathrm{Cr}, \mathrm{Cu}, \mathrm{Fe}, \mathrm{Pb}, \mathrm{Mn}, \mathrm{Cs}, \mathrm{Se}, \mathrm{Ag}, \mathrm{V}, \mathrm{Zn}$ & $\begin{array}{l}\text { Surface water (Class II) } \\
\text { Ground water (Class III) }\end{array}$ \\
\hline Corrosivity & $\mathrm{pH}$ value $=8.26$ & Alkalinity \\
\hline
\end{tabular}

alkaline soil always belongs to a good subgrade filling material because of the easy compaction and great water absorption. Its stable mechanical property determines a huge advantage in rainy weather construction or concrete pavement. Some detailed experimental demonstrations in situ will be conducted in the follow-up study to perform environment impact assessment of SOF, and that will be the focus of subsequent research.

\section{Conclusions}

In order to provide a safety assessment for the experimental road of SOF, a series of standardized experiments are performed. Some valuable conclusions are obtained as follows:

(1) In terms of CBR and resilient modulus, the road performance of SOF exceeds the standard requirement of the relevant specifications. It can maintain good performance at bad conditions of low compaction degree and being soaked for a long time.

(2) The dynamic strength of SOF is higher than that of most of original and stabilized soils. By the analysis of Mohr-Coulomb theory, it can be inferred that the friction of SOF mostly contributes to shear strength under high stress conditions, while its cohesion tends to play a more important role under low stress conditions.

(3) The deformation characteristics of SOF conform to the conventional deformation phase and variation trend. The increase rates of plastic deformation and modulus attenuation with repeated vibrations are slightly low, which results in the overall small accumulation settlement. The prediction results by the fitting formula show that the accumulation deformation of SOF after 10 million traffic loadings is far lower than the specified limit of relevant standards. 
(4) According to the environment impact assessment of SOF, the chemical composition during mixing preparation and F-T cycles is basically stable. The leachates are in line with the benchmarks of Class II surface water and Class III ground water. Moreover, the corrosivity analysis is alkalinity with $\mathrm{pH}$ value of 8.26 , which indicates its good workability.

In conclusion, the workability of SOF has been proven to be great theoretically. However, more practical cases are needed to verify the results of laboratory tests, especially for the durability under unfavorable circumstances. Further research will focus on the data acquisition method, in-depth comparison, and environment impact assessment of experimental road.

\section{Data Availability}

The data used to support the findings of this study are available from the corresponding author upon request.

\section{Conflicts of Interest}

The authors declare no conflicts of interest.

\section{Acknowledgments}

This work was funded by Science and Technology Base \& Talent Special Project of Guangxi Province, grant no. AD19245014, and Science and Technology Project of Jilin Province Transportation Department, grant no. $2017 Z$ DGC6.

\section{References}

[1] E. Knaus, J. Killen, K. Biglarbigi, and P. Crawford, "An overview of oil shale resources," ACS Symposium Series, vol. 1032, pp. 3-20, 2010.

[2] C. Yan and X. Jiang, "The utilization of oil shale energy in China," Energy of China, vol. 9, pp. 21-25, 2000, in Chinese.

[3] J. Hou, Y. Ma, S. Li, and J. Teng, "Development and utilization of oil shale worldwide," Chemical Industry and Engineering Process, vol. 34, pp. 1183-1190, 2015, in Chinese.

[4] C. Gen, S. Li, and J. Qian, "New development and utilization of Chinese oil shale," in Proceedings of the 33th Oil Shale Symposium, Colorado School of Mines Golden, Tallinn, EstoniaColorado School of Mines Golden, Tallinn, Estonia, 2013.

[5] M. Smol, J. Kulczycka, A. Henclik, K. Gorazda, and Z. Wzorek, "The possible use of sewage sludge ash (SSA) in the construction industry as a way towards a circular economy," Journal of Cleaner Production, vol. 95, pp. 45-54, 2015.

[6] K. Ghuzlan, G. Al-Khateeb, and A. A. Damrah, "Using oil shale ash waste as a modifier for asphalt binders," Journal of Material Cycles and Waste Management, vol. 15, no. 4, pp. 522-529, 2013.

[7] M. O. J. Azzam and Z. Al-Ghazawi, "Evaluation of incorporating oil shale filler aggregate into hot mix asphalt using Superpave mix design," Construction and Building Materials, vol. 101, pp. 359-379, 2015.

[8] W. Wang, Y. Cheng, G. Tan, Z. Liu, and C. Shi, "Laboratory investigation on high- and low-temperature performances of asphalt mastics modified by waste oil shale ash," Journal of Material Cycles and Waste Management, vol. 20, no. 3, pp. 1710-1723, 2018.

[9] J. P. Turner, Soil Stabilization Using Oil Shale Solid Wastes: Laboratory Evaluation of Engineering Properties, Department of Civil Engineering, University of Wyoming, Laramie, WY, USA, 1991.

[10] J. P. Turner, "Soil stabilization using oil-shale solid waste," Journal of Geotechnical Engineering, vol. 120, no. 4, pp. 646-660, 1994.

[11] A. Koroljova and A. Pototski, "Use of oil shale fly ash as a binder material in stabilization of soft soils," in Proceedings of the 12th International Symposium on Tropical Problems in the Field of Electrical and Power Engineering, pp. 11-16, Kuressaare, Estonia, 2012.

[12] M. Rokainen, A. Koroljova, A. Pototski, H. Puhkim, P. Lahtinen, and O. Kiviniemi, "Utilization of oil shale ashes in road construction," in Proceedings of Nordic Geotechnical Meeting, pp. 1-10, Copenhagen, Denmark, May 2012.

[13] H. Wei, Y. Zhang, F. Wang, G. Che, and Q. Li, "Experimental research on resilient modulus of silty clay modified by oil shale ash and fly ash after freeze-thaw cycles," Applied Sciences, vol. 8, no. 8, p. 1298, 2018.

[14] Y. Zhang, "Research on dynamic properties and deformation characteristics of subgrade filling modified by oil shale wastes in seasonally frozen area," $\mathrm{Ph}$. D. thesis, Jilin University, Changchun, China, 2019, in Chinese.

[15] J. Cui, "Research on stability of subgrade soil modified by oil shale waste residue and fly ash," Master's thesis, Changchun, China, 2018, in Chinese.

[16] A. Mohajerani, S. Lound, G. Liassos, H. Kurmus, A. Ukwatta, and M. Nazari, "Physical, mechanical and chemical properties of biosolids and raw brown coal fly ash, and their combination for road structural fill applications," Journal of Cleaner Production, vol. 166, pp. 1-11, 2017.

[17] K. Deb and Y. K. Narnaware, "Strength and compressibility characteristics of fiber-reinforced subgrade and their effects on response of granular fill-subgrade system," Transportation in Developing Economies, vol. 1, no. 2, p. 1, 2015.

[18] R. Murthy, S. Nazarian, and M. Picornell, "Dynamic properties of naturally-cemented silt," in Proceedings of Geotechnical Earthquake Engineering \& Soil Dynamics Congress IV, pp. 1-8, Sacramento, CA, USA, 2008.

[19] S. Baig, M. Picornell, and S. Nazarian, "Low strain shear moduli of cemented sands," Journal of Geotechnical and Geoenvironmental Engineering, vol. 123, no. 6, pp. 540-545, 1997.

[20] P. M. Gallagher and J. K. Mitchell, "Influence of colloidal silica grout on liquefaction potential and cyclic undrained behavior of loose sand," Soil Dynamics and Earthquake Engineering, vol. 22, no. 9-12, pp. 1017-1026, 2002.

[21] Ministry of Transport of the People's Republic of China, Test Methods of Soils for Highway Engineering (JTG E40-2007), China Communications Press, Beijing, China, 2007, in Chinese.

[22] Ministry of Transport of People's Republic of China, Specifications for Design of Highway Subgrades (JTG D30-2015), China Communications Press, Beijing, China, 2015.

[23] S. Sağlam and B. S. Bakır, "Cyclic response of saturated silts," Soil Dynamics and Earthquake Engineering, vol. 61, pp. 164175, 2014.

[24] J. Wang, H. Liu, C. Wu, and X. Qu, "Influence of freeze-thaw cycles on dynamic characteristics of subgrade soils with 
different plasticity indices," Chinese Journal of Geotechnical Engineering, vol. 36, pp. 633-639, 2014.

[25] Y. Cai, Q. Sun, L. Guo, C. H. Juang, and J. Wang, "Permanent deformation characteristics of saturated sand under cyclic loading," Canadian Geotechnical Journal, vol. 52, no. 6, pp. 795-807, 2015.

[26] S. K. Navaratnarajah and B. Indraratna, "Use of rubber mats to improve the deformation and degradation behavior of rail ballast under cyclic loading," Journal of Geotechnical and Geoenvironmental Engineering, vol. 143, no. 6, Article ID 04017015, 2017.

[27] Ministry of Railways of People's Republic of China, Code for Design of Railway Earth Structure (TB10001-2016), China Communications Press, Beijing, China, 2016.

[28] Ministry of Ecology and Environment of People's Republic of China, Environmental Quality Standards for Surface Water (GB 3838-2002), China Communications Press, Beijing, China, 2002.

[29] General Administration of Quality Supervision, Inspection and Quarantine of People's Republic of China, Standard for Groundwater Quality (GB 14848-2017), China Communications Press, Beijing, China, 2017.

[30] Ministry of Ecology and Environment of People's Republic of China, Identification Standards for Hazardous Wastes-Identification for Extraction Toxicity (GB 5085.3-2007), China Communications Press, Beijing, China, 2007. 